\title{
Defining a Standard Set of Patient-centered Outcomes for Men with Localized Prostate Cancer
}

\begin{abstract}
Neil E. Martin ${ }^{a, b, 1, *}$, Laura Massey ${ }^{a, 1}$, Caleb Stowell ${ }^{a}$, Chris Bangma $^{c}$, Alberto Briganti $^{d}$, Anna Bill-Axelson ${ }^{e}$, Michael Blute ${ }^{f}$, James Catto ${ }^{g}$, Ronald C. Chen ${ }^{h}$, Anthony V. D'Amico ${ }^{b}$, Günter Feick ${ }^{i}$, John M. Fitzpatrick ${ }^{j}$, Steven J. Frank ${ }^{k}$, Michael Froehner ${ }^{l}$, Mark Frydenberg ${ }^{m}$, Adam Glaser ${ }^{n}$, Markus Graefen $^{o}$, Daniel Hamstra $^{p}$, Adam Kibel $^{q}$, Nancy Mendenhall $^{r}$, Kim Moretti ${ }^{s}$, Jacob Ramon ${ }^{t}$, Ian Roos ${ }^{u}$, Howard Sandler ${ }^{v}$, Francis J. Sullivan ${ }^{w}$, David Swanson $^{x}$, Ashutosh Tewari ${ }^{y}$, Andrew Vickers ${ }^{z}$, Thomas Wiegel ${ }^{\text {aa }}$, Hartwig Huland ${ }^{o}$

${ }^{a}$ International Consortium for Health Outcomes Measurement, Cambridge, MA, USA; ${ }^{\mathrm{b}}$ Department of Radiation Oncology, Dana-Farber/Brigham and Women's Cancer Center, Harvard Medical School, Boston, MA, USA; ${ }^{\mathrm{c}}$ Department of Urology, Erasmus Medical Center, Rotterdam, The Netherlands; ${ }^{\mathrm{d}}$ Prostate Cancer Research Programme at the Urological Research Institute, Department of Urology, Vita-Salute San Raffaele University Hospital, Milan, Italy; ${ }^{\mathrm{e}}$ Department of Surgical Sciences, Department of Urology, Uppsala University Hospital and National Prostate Cancer Register of Sweden, Uppsala, Sweden; ${ }^{\mathrm{f}}$ Department of Urology, Massachusetts General Hospital, Harvard Medical School, Boston, MA, USA; ${ }^{\mathrm{g}}$ University of Sheffield Academic Urology Unit and Academic Unit of Molecular Oncology, CR-UK/YCR, Sheffield Cancer Research Centre, University of Sheffield Medical School, Sheffield, UK; ${ }^{\mathrm{h}}$ Department of Radiation Oncology, University of North Carolina Lineberger Comprehensive Cancer Center, Chapel Hill, NC, USA; ${ }^{\mathrm{i}}$ Bundesverband Prostatakrebs Selbsthilfe, Pohlheim, Germany; ${ }^{\mathrm{j}}$ Irish Cancer Society, Dublin, Ireland; ${ }^{\mathrm{k}}$ Department of Radiation Oncology, University of Texas MD Anderson Cancer Center, Houston, TX, USA; ${ }^{1}$ Department of Urology, University Hospital Carl Gustav Carus, Technische Universität Dresden, Dresden, Germany; ${ }^{\mathrm{m}}$ Department of Surgery, Monash University, Victoria, Australia; ${ }^{\mathrm{n}}$ Leeds Teaching Hospitals NHS Trust, Leeds, West Yorkshire, UK; ${ }^{\circ}$ Martini-Klinik at University Medical Center Hamburg-Eppendorf, Hamburg, Germany; ${ }^{\mathrm{p}}$ Department of Radiation Oncology, University of Michigan Health System, Ann Arbor, MI, USA; ${ }^{\mathrm{q}}$ Urologic Surgery, Brigham and Women's Hospital, Harvard Medical School, Boston, MA, USA; ${ }^{\mathrm{r}}$ University of Florida Proton Therapy Institute, Jacksonville, FL, USA; ${ }^{\mathrm{s}}$ South Australian Prostate Cancer Clinical Outcomes Collaborative, Repatriation General Hospital, Daw Park, South Australia, Australia; ${ }^{\mathrm{t}}$ Department of Urology and Uro-Oncology, Chaim Sheba Medical Center at Tel Hashomer, Tel Hashomer, Israel; " Cancer Voices Australia, Melbourne, Victoria, Australia;

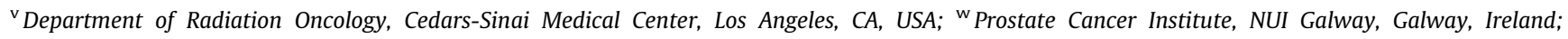
${ }^{\mathrm{x}}$ Department of Urology, University of Texas MD Anderson Cancer Center, Houston, TX, USA; ${ }^{\mathrm{y}}$ Department of Urology, Icahn School of Medicine at Mount Sinai Hospital, New York, NY, USA; ${ }^{\mathrm{z}}$ Department of Epidemiology and Biostatistics, Memorial Sloan-Kettering Cancer Center, New York, NY, USA; ${ }^{\text {aa }}$ Department of Radiation Oncology, University Hospital Ulm, Ulm, Germany
\end{abstract}

\section{Article info}

Article history:

Accepted August 29, 2014

\section{Keywords:}

Outcome measurement

Patient-reported

\begin{abstract}
Background: Value-based health care has been proposed as a unifying force to drive improved outcomes and cost containment.

Objective: To develop a standard set of multidimensional patient-centered health outcomes for tracking, comparing, and improving localized prostate cancer (PCa) treatment value. Design, setting, and participants: We convened an international working group of patients, registry experts, urologists, and radiation oncologists to review existing data and practices. Outcome measurements and statistical analysis: The group defined a recommended standard set representing who should be tracked, what should be measured and at what time points, and what data are necessary to make meaningful comparisons. Using a

\footnotetext{
1 These authors are co-first authors.

* Corresponding author. Department of Radiation Oncology, Dana-Farber/Brigham and Women's Cancer Center, 75 Francis Street, ASB1-L2, Boston, MA 02115, USA. Tel. +1 617732 6433;

Fax: +1 6172645242 .
}

E-mail address: nmartin@lroc.harvard.edu (N.E. Martin).
\end{abstract}


Prostate cancer

Value modified Delphi method over a series of teleconferences, the group reached consensus for the Standard Set.

Results and limitations: We recommend that the Standard Set apply to men with newly diagnosed localized PCa treated with active surveillance, surgery, radiation, or other methods. The Standard Set includes acute toxicities occurring within 6 mo of treatment as well as patient-reported outcomes tracked regularly out to $10 \mathrm{yr}$. Patientreported domains of urinary incontinence and irritation, bowel symptoms, sexual symptoms, and hormonal symptoms are included, and the recommended measurement tool is the Expanded Prostate Cancer Index Composite Short Form. Disease control outcomes include overall, cause-specific, metastasis-free, and biochemical relapse-free survival. Baseline clinical, pathologic, and comorbidity information is included to improve the interpretability of comparisons.

Conclusions: We have defined a simple, easily implemented set of outcomes that we believe should be measured in all men with localized PCa as a crucial first step in improving the value of care.

Patient summary: Measuring, reporting, and comparing identical outcomes across treatments and treatment centers will provide patients and providers with information to make informed treatment decisions. We defined a set of outcomes that we recommend being tracked for every man being treated for localized prostate cancer. (C) 2014 European Association of Urology. Published by Elsevier B.V. This is an open access article under the CC BY-NC-ND license (http://creativecommons.org/licenses/

by-nc-nd/3.0/)

\section{Introduction}

Localized prostate cancer (PCa) represents the most common noncutaneous malignancy afflicting men in Western countries, with a variety of management approaches including surgery, radiation, and active surveillance that are widely used. Variations in PCa outcomes have been observed based on institutional and physician differences [1,2]. In the face of increasing treatment costs [3] and with uncertain outcome gains [4,5], value-based decisions about how, when, and where to treat men with PCa are needed.

Value, defined as a patient's outcomes divided by the cost to achieve those outcomes, has been proposed as a unifying force to improve care quality [6]. As part of an integrated framework for reforming how care is delivered, the need to measure value has become increasingly pressing [7]. Key to measuring value is defining condition-specific outcomes that matter to patients. These include disease control, complications of treatment, and long-term quality of life, although their relative importance varies among individuals [8]. Outcome measures currently are inconsistently collected and reported, limiting the direct population comparisons necessary to improve value. This is particularly true in the setting of patient-reported outcome measures (PROMs), for which many validated instruments are available for domains of urinary incontinence, urinary obstruction, bowel irritation, and sexual dysfunction [9,10]. Efforts to integrate both established disease control measures and patient-reported outcomes (PROs) are taking place within registries [11], but we do not yet have global standards for which measures to include.

Systematic outcome measurements can guide institutional improvements [12], foster dissemination of best practices, and ultimately drive competition around value [13]. We currently lack a common multidimensional definition of the key outcomes for men with localized PCa that physicians need to track to make meaningful comparisons. Using an international working group composed of patients, registry representatives, urologists, and radiation oncologists, we undertook this project to define a set of outcomes that mattered most to men with localized PCa and that we recommend all providers track.

\section{Methods}

The goal of this working group was to define a set of 10-15 key outcomes and related risk factors, called the Standard Set, that should be tracked for all patients with localized PCa in any country. We used a structured consensus-driven modified Delphi method including a combination of teleconferences and surveys to debate proposals based on evidence and expert opinions from the project team and agreed to define the Standard Set. From June to December 2013, the group convened for six teleconferences, five of which were followed by surveys to gather feedback and make decisions on the points discussed. The group used a two-thirds threshold to determine when a particular point was decided.

The working group was convened and organized by the International Consortium for Health Outcomes Measurement (ICHOM), a nonprofit organization focused on the development of standard sets of outcomes and risk factors by medical condition. Working group members were invited to participate by peers from a smaller project team (N.M., L.M., C.S., M.G., and H.H.) that coordinated and led the group's activities. ICHOM had access to all the data during the project, but ICHOM, its funders, and the funders of this project had no editorial control over the final publication.

\section{Results}

\subsection{Condition scope}

The Standard Set was designed around men with clinical American Joint Committee of Cancer (AJCC) stages T1-T4 localized PCa treated with curative intent or followed with active surveillance. Based on screening studies in the United States and Europe, we believe this scope covers $>90 \%$ of men with newly diagnosed PCa $[14,15]$. A separate working group has been convened to define relevant outcomes for men with metastatic PCa.

\subsection{Treatments}

The treatments listed in Table 1 alone or in combination (eg, radical prostatectomy followed by adjuvant external-beam 
radiation) including active surveillance are covered by this set. We only included treatment details we believed were essential for comparisons, and as a result, the treatments are specified at the level of nerve sparing or non-nerve sparing for surgery and the dose and fraction size for radiation. We expect that centers will continue to collect additional treatment-related and process details that would be necessary for sharing best practices.

\subsection{Survival and disease control}

Knowledge of treatment efficacy is crucial for decision making for most men with PCa [8]. We selected overall survival, cause-specific survival, metastasis-free survival, and biochemical recurrence-free survival as measures of cancer eradication for the Standard Set. Although some of these outcomes such as prostate-specific antigen (PSA) recurrence are intermediate end points, they correlate highly with patient anxiety and initiation of additional therapy, warranting their inclusion in the set.

We recommend collecting survival and disease control outcomes annually until death, recognizing this represents a significant burden to many centers but is crucial to understand the ultimate benefit of treatment. We recognize that typical follow-up may eventually transfer back to primary care physicians and salvage therapies may occur at other facilities, and we advocate the development of health information exchanges to track these outcomes across settings. In their absence, institutions may need to collect and abstract records from the currently treating institution if the patient has transferred care.

\subsection{Complications}

Treatment complications are a central concern for patients [8] and can have a significant impact on long-term outcomes. Although many treatment-related toxicity scales exist, we focused on those in common practice today. For nonsurgically treated patients, we selected the Common Terminology Criteria for Adverse Events (CTCAE) v.4. This grading platform was designed as a comprehensive grading system for the adverse effects of cancer treatment and is commonly used in clinical trials. For surgically treated patients, we recommend the Clavien-Dindo classification [16]. We suggest collecting all grade $\geq 3$ toxicities occurring within the first 6 mo following local treatment along with the adverse event name in the CTCAE.

\subsection{Patient-reported health status}

Given the frequency with which physicians underestimate health-related quality of life in patients with PCa, PROMs have been widely implemented $[9,10]$. Our goal was to recommend a single PROM addressing the pertinent domains to limit variability in assessment between treatment modalities and centers. This was a contentious decision because centers of excellence have established prospective registries using various measures in $\mathrm{PCa}$, and there is no compelling evidence for the advantage of one particular
PROM over another. However, to give clear advice to centers and registries beginning their development, and in the hopes of moving existing efforts toward alignment on measure definitions over time, we included a consensus recommendation for a single instrument: the Expanded Prostate Cancer Index Composite 26-question short form (EPIC-26) [17].

Other excellent PROMs related to the outcomes following PCa treatment exist $[10,18-20]$, and our recommendation for centers not yet ready to switch to the EPIC-26, or for centers with compelling reasons to use other validated PROMs, would be to collect the same domains at the same time points and develop cross-talk algorithms to allow meaningful comparisons with those tracking the set. We recognize that a 16-question version of EPIC designed for easy implementation clinically has now been validated [19], but due to the absence of a question on rectal bleeding, an important late toxicity from radiation, we continue to recommend the 26 -item questionnaire at present. We also included three additional questions regarding sexual interest and the use of sexual medication and devices in the set to improve the interpretability of the sexual function domain from the EPIC-26 (Table 1).

Men with $\mathrm{PCa}$ also frequently experience symptoms outside the urinary, bowel, and sexual domains commonly tracked that have an impact on their quality of life. A variety of regularly used general health-related quality of life PROMs exist including the EuroQOL five dimensions questionnaire (EQ-5D), 12-item Short Form Health Survey (SF-12), Functional Assessment of Cancer Therapy: General (FACT-G), and the cancer-specific European Organization for Research and Treatment of Cancer Quality of Life Questionnaire (QLQ-C30) [21]. Ultimately, we did not feel the measurement of general health-related quality of life was an essential component of the first version of this localized PCa set, and we recommend that interested centers consider using one such tool based on their specific needs. We were also interested in including specific measures for fatigue, anxiety, and time to return to normal functioning. All are key outcomes associated with the treatment of localized PCa but have not been commonly integrated into general PCa PROMs. We advocate the continued development of concise PROMs focused on these domains for men with localized PCa.

We recommend assessing the PROs at baseline, prior to treatment, at 6 mo following treatment, and then annually at years 1-10 following treatment or until the development of metastatic disease (Fig. 1). Although many of the side effects of treatment are apparent in the first few years of follow-up [9], changes in PROs have been observed with longer term data collection [22]. In choosing $10 \mathrm{yr}$, we attempted to balance the desire for complete follow-up with cost and logistical concerns. We recognize that for many centers and countries, it may be a long journey to reach this goal.

The use of adjuvant versus salvage radiation following prostatectomy remains controversial, and in this set, we recommend continued collection of PROs in both situations. Similarly, PROs after other salvage options such as brachytherapy and surgery should be collected following treatment. 
Table 1 - Summary of the International Consortium for Health Outcomes Measurement Standard Set for localized prostate cancer

\begin{tabular}{|c|c|c|c|c|}
\hline & Measure & Details & Timing & Data source \\
\hline \multirow[t]{8}{*}{$\begin{array}{l}\text { Treatment } \\
\text { approaches } \\
\text { included }\end{array}$} & Active surveillance & & $\begin{array}{l}\text { At } 6 \text { mo after } \\
\text { treatment } \\
\text { initiation }\end{array}$ & $\begin{array}{l}\text { Clinical data } \\
\text { abstraction }\end{array}$ \\
\hline & Watchful waiting & & & \\
\hline & Radical prostatectomy ${ }^{*}$ & $\begin{array}{l}\text { Nerve sparing or non-nerve } \\
\text { sparing }\end{array}$ & & \\
\hline & External-beam radiation therapy & $\begin{array}{l}\text { Total dose and dose per } \\
\text { fractions }\end{array}$ & & \\
\hline & Brachytherapy* & High- or low-dose rate & & \\
\hline & ADT $^{*}$ & $\begin{array}{l}\text { Was ADT part of the primary } \\
\text { treatment? }\end{array}$ & & \\
\hline & Focal therapy* & & & \\
\hline & Other & & & \\
\hline \multirow[t]{12}{*}{$\begin{array}{l}\text { Baseline } \\
\text { characteristics }\end{array}$} & Age & Date of birth & $\begin{array}{l}\text { Prior to } \\
\text { treatment }\end{array}$ & $\begin{array}{l}\text { Administrative or } \\
\text { patient reported }\end{array}$ \\
\hline & Body mass index & Height and weight & & Clinical data \\
\hline & Date of diagnosis & Date of initial diagnosis & & Clinical data \\
\hline & $\begin{array}{l}\text { Modified Charlson Comorbidity Index } \\
\text { questionnaire }\end{array}$ & Patient reported ${ }^{\#}$ & & Patient reported \\
\hline & PSA & $\begin{array}{l}\text { Most recent PSA value before } \\
\text { histologic diagnosis }\end{array}$ & & Clinical data \\
\hline & AJCC 7th ed. clinical stage & $\begin{array}{l}\text { cT category, cN category, and } \\
\text { cM category }\end{array}$ & & Clinical data \\
\hline & No. of biopsy cores involved & $\begin{array}{l}\text { No. of cores taken; no. of } \\
\text { cores positive }\end{array}$ & & Clinical data \\
\hline & $\begin{array}{l}\text { Greatest percentage involvement of biopsy } \\
\text { cores }\end{array}$ & $\begin{array}{l}\text { Greatest percentage } \\
\text { involvement from biopsy } \\
\text { results }\end{array}$ & & Clinical data \\
\hline & Biopsy Gleason score & $\begin{array}{l}\text { The highest primary and } \\
\text { secondary Gleason grade }\end{array}$ & & Clinical data \\
\hline & AJCC 7th ed. pathologic stage & pT category, pN category & $\begin{array}{l}\text { Following } \\
\text { surgery }\end{array}$ & Clinical data \\
\hline & Margin status & $\begin{array}{l}\text { Negative/Positive (if positive, } \\
\text { focal/multifocal) }\end{array}$ & & Clinical data \\
\hline & Prostatectomy Gleason score & $\begin{array}{l}\text { The highest primary and } \\
\text { secondary Gleason grade }\end{array}$ & & Clinical data \\
\hline \multirow{2}{*}{$\begin{array}{l}\text { Acute } \\
\text { complications } \\
\text { (within } 6 \text { mo } \\
\text { of treatment) }\end{array}$} & Surgery patients: Clavien classification & $\begin{array}{l}\text { Presence or absence of } \\
\text { grade } \geq 3\end{array}$ & $\begin{array}{l}\text { At } 6 \text { mo after } \\
\text { treatment } \\
\text { initiation }\end{array}$ & $\begin{array}{l}\text { Clinical or patient } \\
\text { reported }\end{array}$ \\
\hline & Radiation patients: CTCAE classification & $\begin{array}{l}\text { Presence or absence of grade } \\
\geq 3 \text { including name of the } \\
\text { adverse event }\end{array}$ & & \\
\hline \multirow[t]{4}{*}{$\begin{array}{l}\text { Survival and } \\
\text { disease control }\end{array}$} & Overall survival & Date of death & $\begin{array}{l}\text { Evaluated at } \\
\text { least annually } \\
\text { until death }\end{array}$ & $\begin{array}{l}\text { Administrative } \\
\text { data }\end{array}$ \\
\hline & Cause-specific survival & $\begin{array}{l}\text { Was death attributed to } \\
\text { prostate cancer on death } \\
\text { certificate? }\end{array}$ & & $\begin{array}{l}\text { Administrative } \\
\text { data }\end{array}$ \\
\hline & Metastasis-free survival & $\begin{array}{l}\text { Indicated date of metastatic } \\
\text { disease if applicable and } \\
\text { whether it was diagnosed } \\
\text { clinically or radiographically }\end{array}$ & & $\begin{array}{l}\text { Clinical or patient } \\
\text { reported }\end{array}$ \\
\hline & Biochemical recurrence-free survival & $\begin{array}{l}\text { Indicate date of PSA } \\
\text { recurrence if applicable } \\
\text { All PSAs and dates following } \\
\text { treatment should be } \\
\text { recorded }\end{array}$ & & $\begin{array}{l}\text { Clinical or patient } \\
\text { reported }\end{array}$ \\
\hline
\end{tabular}


Table 1 (Continued)

\begin{tabular}{|c|c|c|c|c|}
\hline & Measure & Details & Timing & Data source \\
\hline \multirow[t]{5}{*}{$\begin{array}{l}\text { Patient-reported } \\
\text { health status }\end{array}$} & Urinary incontinence domain scores & $\begin{array}{l}\text { EPIC-26 urinary incontinence } \\
\text { domain }\end{array}$ & $\begin{array}{l}\text { At baseline, } \\
6 \text { mo after } \\
\text { treatment, and } \\
\text { then annually } \\
\text { following } \\
\text { treatment until } \\
10 \text { yr or the } \\
\text { diagnosis of } \\
\text { metastatic } \\
\text { disease }\end{array}$ & Patient reported \\
\hline & Urinary irritative/Obstructive scores & $\begin{array}{l}\text { EPIC-26 urinary irritative/ } \\
\text { obstructive domain }\end{array}$ & & \\
\hline & Bowel symptom scores & EPIC-26 bowel domain & & \\
\hline & Sexual symptom scores & $\begin{array}{l}\text { EPIC-26 sexual domain; two } \\
\text { additional questions from } \\
\text { EORTC QLQ-PR25 scale and } \\
\text { one from validated scale on } \\
\text { erectile dysfunction aids } \ddagger\end{array}$ & & \\
\hline & $\begin{array}{l}\text { Hormonal symptom scores (for men receiving } \\
\text { ADT) }\end{array}$ & EPIC-26 hormonal domain & & \\
\hline
\end{tabular}

$\mathrm{ADT}=$ androgen-deprivation therapy; AJCC = American Joint Committee on Cancer; CTCAE = Common Terminology Criteria for Adverse Events; EORTC = European Organization for Research and Treatment of Cancer; EPIC $=$ Expanded Prostate Cancer Index Composite; PSA = prostate-specific antigen; QLQ-PR25 = Quality of Life Questionnaire-Prostate Module.

These should also be collected as salvage treatments as necessary.

\# "Have you ever been told by a doctor that you have any of the following? Heart disease (eg, angina, heart attack, or heart failure), high blood pressure, leg pain when walking due to poor circulation, lung disease (eg, asthma, chronic bronchitis, or emphysema), diabetes, kidney disease, liver disease, problems caused by stroke, disease of the nervous system (eg, Parkinson disease or multiple sclerosis), other cancer (within the last 5 yr), depression, arthritis, HIV/AIDS?" (yes or no to each) [24].

‡ (1)“During the last $4 \mathrm{wk}$, to what extent were you interested in sex?" (not at all, a little, quite a bit, very much) [20], (2) "Have you used any medications or devices to aid or improve erections?" (yes, no), and (3) "For each of the following medications and devices, please indicate whether or not you have tried or currently use it to improve your erections: Viagra or other pill, Muse (intraurethral alprostadil suppository), penile injection therapy (such as Caverject), vacuum erection device (such as ErecAid), other" (have not tried it; tried it, but it was not helpful; it helped, but I am not using it now; it helped and I use it sometimes; it helped and I use it always) [26].

(a)

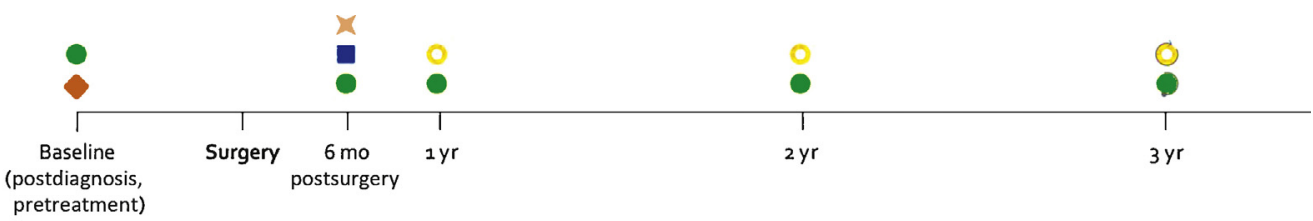

(b)

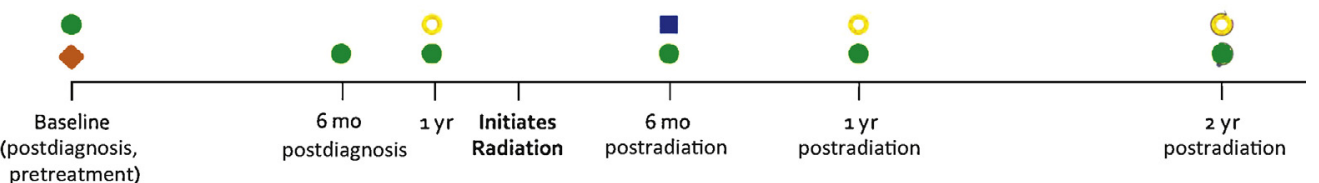

(c)

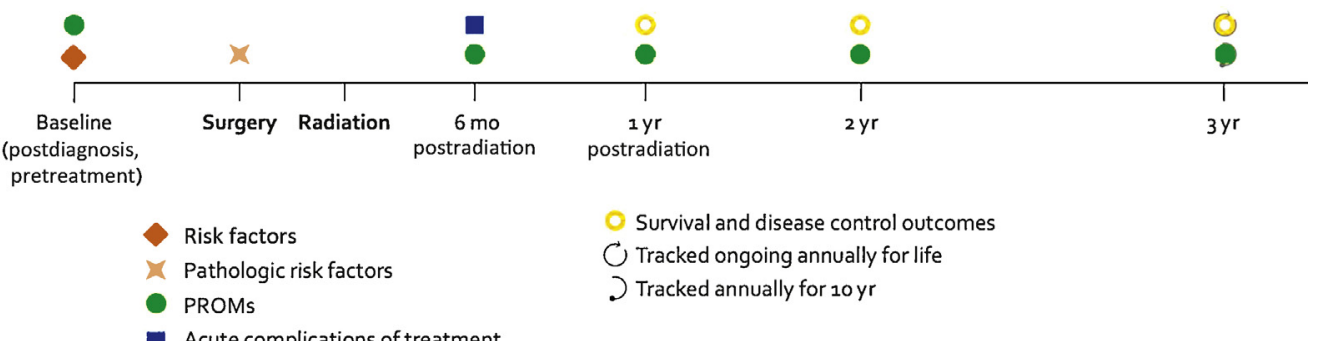

Fig. 1 - Selected sample timelines illustrating when particular outcomes and baseline factors should be collected for patients treated with different modalities including (a) surgery, (b) active surveillance followed by radiation, and (c) surgery with adjuvant radiation. These timelines are intended to represent the outcome data collection points for possible treatment paths that a patient could take; they are not intended to advocate a particular treatment approach.

PROMS = patient-reported outcome measures. 


\subsection{Baseline characteristics}

Baseline clinical and pathologic factors are associated with both disease control and quality of life outcomes in PCa. Outlined in Table 1, the working group identified the baseline data necessary to make meaningful comparisons between patients. Numerous factors are associated with clinical outcomes following treatment for $\mathrm{PCa}$, and the group focused on collecting established factors including PSA level, Gleason score, number of positive cores, and the percentage involvement of the core. Recognizing the long natural history of localized PCa and the high relative rate of death from other causes, measures of comorbidity were also included [23]. The working group recommended the use of the body mass index and a modified patient-reported Charlson Comorbidity Index (CCI) questionnaire to collect a list of comorbid diseases. A similar version has been shown to correlate well with a physician-reported CCI [24], and the decision to select this tool as opposed to other established measures was made in part pragmatically to avoid reliance on claims or clinically abstracted data for comorbidities. We recommend that these risk data be collected before treatment initiation. For men undergoing radical prostatectomy, additional pathologic data including stage, Gleason score, and margin status should be collected after surgery.

\subsection{Data collection}

A very important long-term goal of this effort is to produce data that can be easily compared between providers, centers, and countries. To achieve this, we recommend processes to reduce variability including the use of similar data sources, recognizing that the specific details of data collection will necessarily differ by center. As outlined in Table 1, the potential sources include claims data and death registries, patient-reported sources, and clinical abstraction or physician-reported sources, and we recommend that the source of data as well as the response rate (if patient reported) be tracked for every measure.

The Standard Set is consistent with a data dictionary from a registry, but in the face of regulatory, privacy, and information technology challenges, we advocate that centers without a national registry track these data individually with the anticipation that future efforts led by ICHOM will facilitate standardized comparisons between centers measuring this set.

A data collection manual that further describes each measure, its definition, inclusion and exclusion criteria, and potential data sources is available on the ICHOM Web site (www.ichom.org/project/localized-prostate-cancer).

\section{Discussion}

Value-based health care has the potential to align patients, providers, and payers toward the common goal of improving outcomes and lowering costs. A current barrier to its adoption is the absence of standardized outcomes that are meaningful to patients [25]. We convened a working group composed of patients, registry experts, urologists, and radiation oncologists to define a standard set of outcomes and risk factors that should be measured for all men with localized PCa.

This cross-disciplinary effort should improve the consistency of data we present to patients as they approach decisions regarding treatment. This was an important goal for our working group because it recognizes the difficulties and uncertainties men face at the time of diagnosis. We acknowledge that randomized studies remain the gold standard for outcome comparisons between treatments, but registries serve as essential companion efforts to assess the effectiveness of treatments in real-world settings. As a minimum set, we acknowledge that this effort cannot address all potentially important variability including Gleason interpretation, PSA assay variability, and all pertinent treatment details.

This project was made dramatically easier by a broad and deep literature focused on PROs following treatment of localized PCa. In fact, this breadth and depth challenged us to pick from a variety of excellent PROMs and outcome definitions. With an aim at parsimony, commonly used tools like the International Prostate Symptom Score and International Index of Erectile Function were not included because these domains are covered by the EPIC-26. Many practices routinely use these and other PROMs as part of regular clinical care, and we recognize that switching to or adding the EPIC26 may cause some disruption in longitudinal data. We advocate future work to make commonly used PCa PROMs comparable, allowing for a more seamless transition to a universal standard.

Computer-adaptive PROMs are under investigation currently and may ultimately replace approaches such as the EPIC-26, for which men are asked questions regardless of whether they affirm to have symptoms in a specific domain. We recognize that widespread adoption will also require PROM translations to ensure comparability across populations.

Broad adoption of this Standard Set will also enable a global network of providers to learn from each other by comparing meaningful differences in the outcomes for their patients. Existing observational data show wide variations in PCa outcomes based on institutional and physician differences and suggest significant room for improvement $[1,2]$.

We recognize that in many countries, significant financial and logistical challenges remain to collect the various forms of outcome data: administrative, patient-reported, and abstracted data. However, recent investments in registry infrastructure, such as those in Ireland, Canada, Australia, and the United States, and increased focus on leveraging health information technology investments for quality reporting suggest that these barriers will become less significant over time.

\section{Conclusions}

Through the efforts reported in this paper, we have defined a relatively simple, easily implemented set of outcomes that we believe should be measured in all men with localized 
PCa. This is a first step in an effort to drive what we hope are meaningful and significant improvements in the care of all men with this common disease.

Author contributions: Neil E. Martin had full access to all the data in the study and takes responsibility for the integrity of the data and the accuracy of the data analysis.

Study concept and design: Martin, Massey, Stowell, Graefen, Huland. Acquisition of data: Martin, Massey, Chen, Vickers.

Analysis and interpretation of data: Martin, Massey.

Drafting of the manuscript: Martin, Massey, Stowell.

Critical revision of the manuscript for important intellectual content: Bangma, Briganti, Bill-Axelson, Blute, Catto, Chen, D’Amico, Feick, Fitzpatrick, Frank, Froehner, Frydenberg, Glaser, Hamstra, Kibel, Mendenhall, Moretti, Ramon, Roos, Sandler, Sullivan, Swanson, Tewari, Vickers, Wiegel, Graefen, Huland.

Statistical analysis: Massey.

Obtaining funding: Stowell.

Administrative, technical, or material support: Massey.

Supervision: None.

Other (specify): None.

Financial disclosures: Neil E. Martin certifies that all conflicts of interest including specific financial interests and relationships and affiliations relevant to the subject matter or materials discussed in the manuscript (eg, employment/affiliation, grants or funding, consultancies, honoraria, stock ownership or options, expert testimony, royalties, or patents filed, received, or pending), are the following: Caleb Stowell is an employee of the International Consortium for Health Outcomes Measurement (ICHOM), which was cofounded by and receives financial support from Michael E. Porter, The Boston Consulting Group, and the Karolinska Institutet; ICHOM also receives general financial support, for which no goods or services are paid in return, from Movember, Carl Bennet $A B$, The Children's Hospital of Philadelphia, Harvard Pilgrim HealthCare, Onze Lieve Vrouwe Gasthuis, The University of Texas MD Anderson Cancer Center, Partners HealthCare, Blue Cross Blue Shield of Massachusetts, Sahlgrenska Universitetssjukhuset, Tenet, Koo Foundation Sun Yat-Sen Cancer Center, Saint Francis Care, Connecticut Joint Replacement Center, The Chaim Sheba Medical Center at Tel Hashomer, Ziekenhuis St. Antonius, and Cooper-Newell Foundation. Ronald C. Chen receives grants from Accuray, Inc. John M. Fitzpatrick earns personal fees from Sanofi-Aventis, Janssen, Astellas, Millennium, and Takeda. Steven J. Frank earns personal fees from C4 Imaging. In addition, he holds US patent 8529872 B2 issued to C4 Imaging and is a board member of the American Brachytherapy Society and the American Radium Society. Michael Froehner reports support for conference participation from Pfizer and Janssen. Daniel Hamstra reports speaker fees from Varian Medical Systems and grants from Novartis. Adam Kibel earns personal fees from Sanofi-Aventis and Dendreon. Howard Sandler earns personal fees from Medivation, Bayer, eviti, and Advanced Medical Isotope Corporation. Francis J. Sullivan receives grants from Ferring Pharmaceuticals and personal fees from Ipsen Pharmaceutics, Janssen, and Bayer Pharmaceutics.

Funding/Support and role of the sponsor: Movember Foundation helped design and conduct the study and collect the data.

\section{References}

[1] Begg CB, Riedel ER, Bach PB, et al. Variations in morbidity after radical prostatectomy. N Engl J Med 2002;346:1138-44.

[2] Chen AB, D'Amico AV, Neville BA, Steyerberg EW, Earle CC. Provider case volume and outcomes following prostate brachytherapy. J Urol 2009;181:113-8, discussion 118 .
[3] Nguyen PL, Gu X, Lipsitz SR, et al. Cost implications of the rapid adoption of newer technologies for treating prostate cancer. J Clin Oncol 2011;29:1517-24.

[4] Sheets NC, Goldin GH, Meyer AM, et al. Intensity-modulated radiation therapy, proton therapy, or conformal radiation therapy and morbidity and disease control in localized prostate cancer. JAMA 2012;307:1611-20.

[5] Hu JC, Gu X, Lipsitz SR, et al. Comparative effectiveness of minimally invasive vs open radical prostatectomy. JAMA 2009;302:1557-64.

[6] Porter ME, Teisberg EO. Redefining health care: creating valuebased competition on results. Boston, MA: Harvard Business School Press; 2006.

[7] Porter ME. What is value in health care? N Engl J Med 2010;363: 2477-81.

[8] Zeliadt SB, Ramsey SD, Penson DF, et al. Why do men choose one treatment over another?: a review of patient decision making for localized prostate cancer. Cancer 2006;106:1865-74.

[9] Sanda MG, Dunn RL, Michalski J, et al. Quality of life and satisfaction with outcome among prostate-cancer survivors. N Engl J Med 2008; 358:1250-61.

[10] Clark JA, Talcott JA. Symptom indexes to assess outcomes of treatment for early prostate cancer. Med Care 2001;39:1118-30.

[11] Ashley L, Jones $\mathrm{H}$, Thomas J, et al. Integrating patient reported outcomes with clinical cancer registry data: a feasibility study of the electronic Patient-Reported Outcomes from Cancer Survivors (ePOCS) system. J Med Internet Res 2013;15:e230.

[12] Talcott JA, Manola J, Chen RC, et al. Using patient-reported outcomes to assess and improve prostate cancer brachytherapy. BJU Int 2014;114:511-6.

[13] Vickers A, Savage C, Bianco F, et al. Cancer control and functional outcomes after radical prostatectomy as markers of surgical quality: analysis of heterogeneity between surgeons at a single cancer center. Eur Urol 2011;59:317-22.

[14] Andriole GL, Crawford ED, Grubb III RL, et al. Mortality results from a randomized prostate-cancer screening trial. N Engl J Med 2009;360: 1310-9.

[15] Schroder FH, Hugosson J, Roobol MJ, et al. Screening and prostatecancer mortality in a randomized European study. N Engl J Med 2009;360:1320-8

[16] Dindo D, Demartines N, Clavien PA. Classification of surgical complications: a new proposal with evaluation in a cohort of 6336 patients and results of a survey. Ann Surg 2004;240:205-13.

[17] Wei JT, Dunn RL, Litwin MS, Sandler HM, Sanda MG. Development and validation of the Expanded Prostate Cancer Index Composite (EPIC) for comprehensive assessment of health-related quality of life in men with prostate cancer. Urology 2000;56:899-905.

[18] Vickers AJ, Savage CJ, Shouery M, Eastham JA, Scardino PT, Basch EM. Validation study of a web-based assessment of functional recovery after radical prostatectomy. Health Qual Life Outcomes 2010;8:82.

[19] Chipman JJ, Sanda MG, Dunn RL, et al. Measuring and predicting prostate cancer related quality of life changes using EPIC for clinical practice. J Urol 2014;191:638-45.

[20] van Andel G, Bottomley A, Fossa SD, et al. An international field study of the EORTC QLQ-PR25: a questionnaire for assessing the health-related quality of life of patients with prostate cancer. Eur J Cancer 2008:44:2418-24.

[21] Aaronson NK, Ahmedzai S, Bergman B, et al. The European Organization for Research and Treatment of Cancer QLQ-C30: a quality-oflife instrument for use in international clinical trials in oncology. J Natl Cancer Inst 1993;85:365-76.

[22] Resnick MJ, Koyama T, Fan KH, et al. Long-term functional outcomes after treatment for localized prostate cancer. N Engl J Med 2013;368:436-45. 
[23] Sarfati D. Review of methods used to measure comorbidity in cancer populations: no gold standard exists. J Clin Epidemiol 2012;65: 924-33.

[24] Habbous S, Chu KP, Harland LT, et al. Validation of a one-page patient-reported Charlson comorbidity index questionnaire for upper aerodigestive tract cancer patients. Oral Oncol 2013;49: 407-12.
[25] Berenson RA, Kaye DR. Grading a physician's value-the misapplication of performance measurement. N Engl J Med 2013;369:2079-81.

[26] Miller DC, Wei JT, Dunn RL, et al. Use of medications or devices for erectile dysfunction among long-term prostate cancer treatment survivors: potential influence of sexual motivation and/or indifference. Urology 2006;68:166-71.

\section{www.esulasers15.org}

\section{2nd ESU Masterclass on Lasers in urology}

In collaboration with the EAU Section of Uro-Technology (ESUT)

4-5 November 2015, Barcelona, Spain

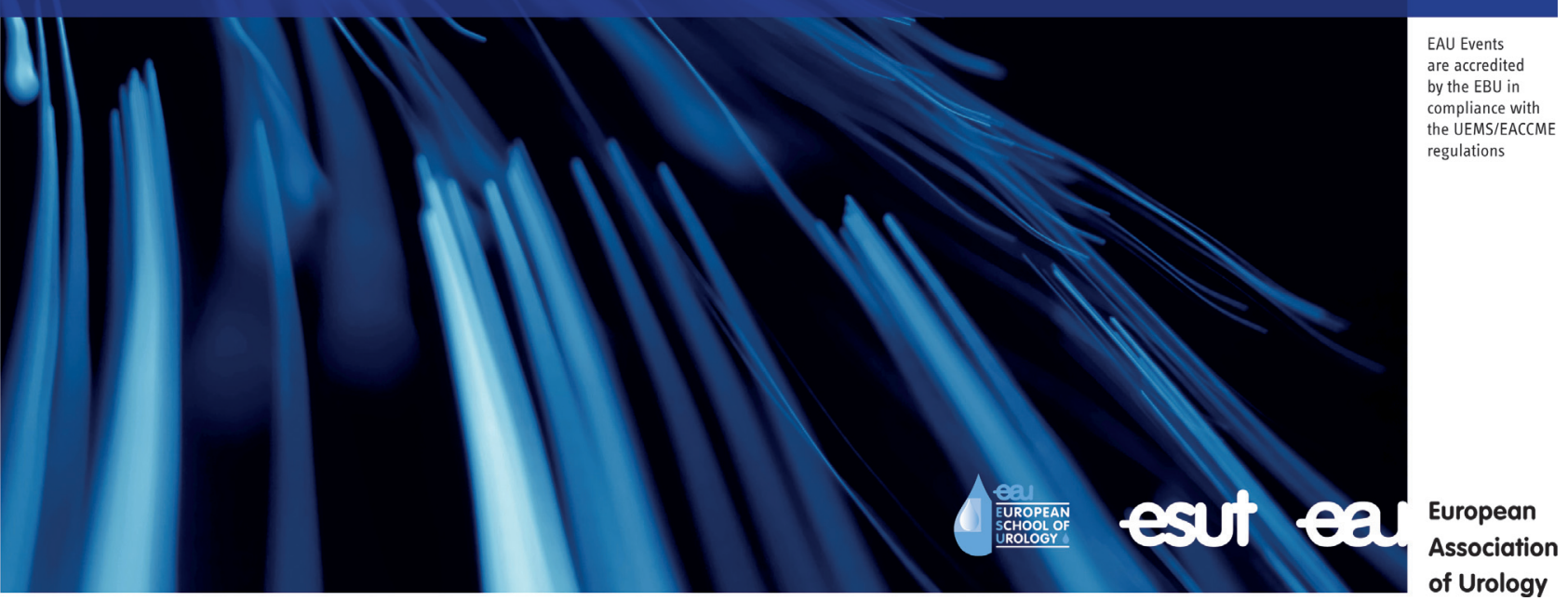

